\title{
Implementation of Home Security System Using Deep Learning Process for Security Applications
}

\author{
Sai Manoj Petluri ${ }^{1}$, G.Sai Charan ${ }^{2}$,M.V.P.B Srinivas ${ }^{3}$, Y.Vignan Kumar $^{4}$, G.Sharavan Kumar ${ }^{5}$ \\ ${ }^{(1,2,3,4)}$ B.Tech Students,Electronics and Communication Engineering, MLR Institute of Technology \\ Hyderabad, Telangana, India. \\ ${ }^{5}$ Associate Professor, Electronics and Communication Engineering, MLR Institute of Technology \\ Hyderabad, Telangana, India.
}

\begin{abstract}
Security has always been an important criteria in regarding home security applications. This project is developed to prevent the entry of unauthorized persons into our home by using facial recognition. The project objective is to monitor and track whether the person is authorized or not. This security system detects the person's face who is at the door, recognizes whether he is authorized or not. If the person is authorized then he gets the access, else the alert message is sent to the house owner. This project is implemented using LabVIEW, Vision builder AI software and myRio. This system is more effective and reliable in terms of code complexity and is user friendly while training the authorized persons.
\end{abstract}

KeyWords: Security system for Home Applications, Access toDoorlock,Facial Detection andRecognition,Securityalert Message .

\section{INTRODUCTION}

Face recognition based Home security system is always efficient in giving access to the person into our house.
Security is most important criteria in smart home applications. The most important part in this project is to detect and recognize the person's face at the door. There are many ways in detecting the person at the door and give him access. Like facial recognition, finger print detection, retina based detection, Radio frequency Identification(RFID) etc.we are using facial recognition to implement the project.

Detection of the person in front of the door is done using a sensor. When the sensor detects the person the circuit is activated. Then the camera which is placed on door is activated and captures the image of the person who is in front of the door.

Thecaptured images are compared with the existing authorized images which are stored in the database . if the person's image is matched with the authorized person image in the database then he is given access into house. If the images does not match then the alert message is sent to the house owner .

This project is implemented in embedded systems domain using LabVIEW and Vision Builder AI softwares and myRIO. The another hardware components used are ir sensor- to detect the person infront of the door, camera, relay- to drive the door lock ,solenoid doorlock, GSM module and power supply. LabVIEW is a graphical programming language which is user friendly and no need of coding. Vision builder AI is a software provided by National Instruments .

Using this software we are training the system to detect and recognize human faces. National Instruments myRIO is a very specific microcontroller that mixes the ability of an ARM processor with the rate of a region Programmable Gate Array (FPGA). The all-in-one package consists of both analog and digital interfaces, with bipolar analog I/O, making it an excellent tool for excessive-pace manipulate. In this project, Pattern matching is $r$ done by using filters on the entire image, and estimating the difference between local and pattern windows. 


\section{Methodlogy}

The primary task is to detect the person at the door. This task is accomplished using IR sensor. It returns the digital value when the person is detected. When the person is detected the IR sensor gets turned on and turns on the entire circuit thus, saving the power consumption. When the circuit gets turned on the camera captures the person image. Before we need to store the authorized person image in Database.Then the captured images are compared with the authorized person images in the data base if the person's image is matched with the authorized person image then the person is given access and signal is sent to the relay which turns on the door lock and the door opens.If the person's image is not matched with the authorized person image the OFF signal is sent to the relay and the door lock gets turns off and the message is sent to the house owner through GSM module.

\section{ALGORITHM FOR FACIAL RECOGNITION}

The first step is to acquire the image in vision builder software. Using Vision assistant the captured image is enhanced, filtered, HSI plane is set for getting good quality intense image and preferable region of interest is selected for pattern matching. Using match pattern option the pattern is matched in accordance with the stored image. Then the patterns drawn on the face coordinate values are set to find the face in the selected coordinate system. The whole result of this pattern matching is generated using set variable option.

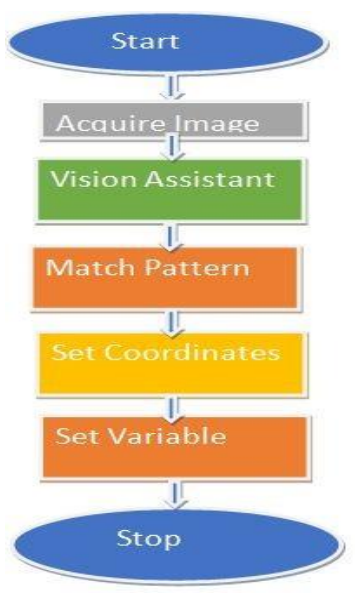

Then a shared variable is created to use the result of facial recognition globally. Using this shared variable of the output variables in MyRio are created.

\section{IMPLEMENTATION}

Firstly the image is captured using acquire image option using USB camera or web camera. Using Vision Builder AI software the image is enhanced and filtered. The System is trained for the facial recognition. The camera is set in continuous acquisition mode to capture the images in regular time intervals. When the camera captures the image, the captured image is compared with the drawn patterns of the original image, in the Vision Builder AI software. The result of the Match pattern option will be True or False. If the result is True then the coordinates are set for further confirmation of the face. If the result of the Set coordinates option is also true then the set variable option assigns true to the global variable. If any of the result is false then the vaiue of the global variable is false.

The global variable value is used in the VI to give the signal to the relay so that it turns on the doorlock, so that the person gets access to the house, in case when the value of the global variable is true. If the value of the global variable is false then the signal is not sent to the relay and thus the doorlock gets turned off, thereby denying the access to the person.

The GSM module gets activated to send the alert message to the house owner.

\section{DESIGN INLABVIEW}

The global variable set in Vision builder software is used to blink the LED. This LED is Data binded with another shared variable in myRio. This shared variable is used to control relay and GSM Module

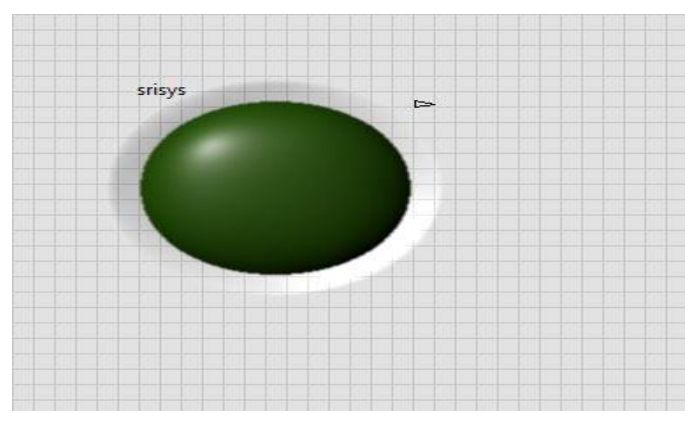

Fig 2: Front pannel in LabVIEW 


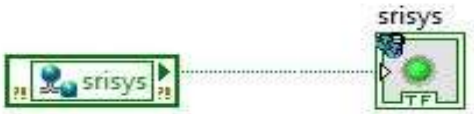

Fig 3: VI in LabVIEW
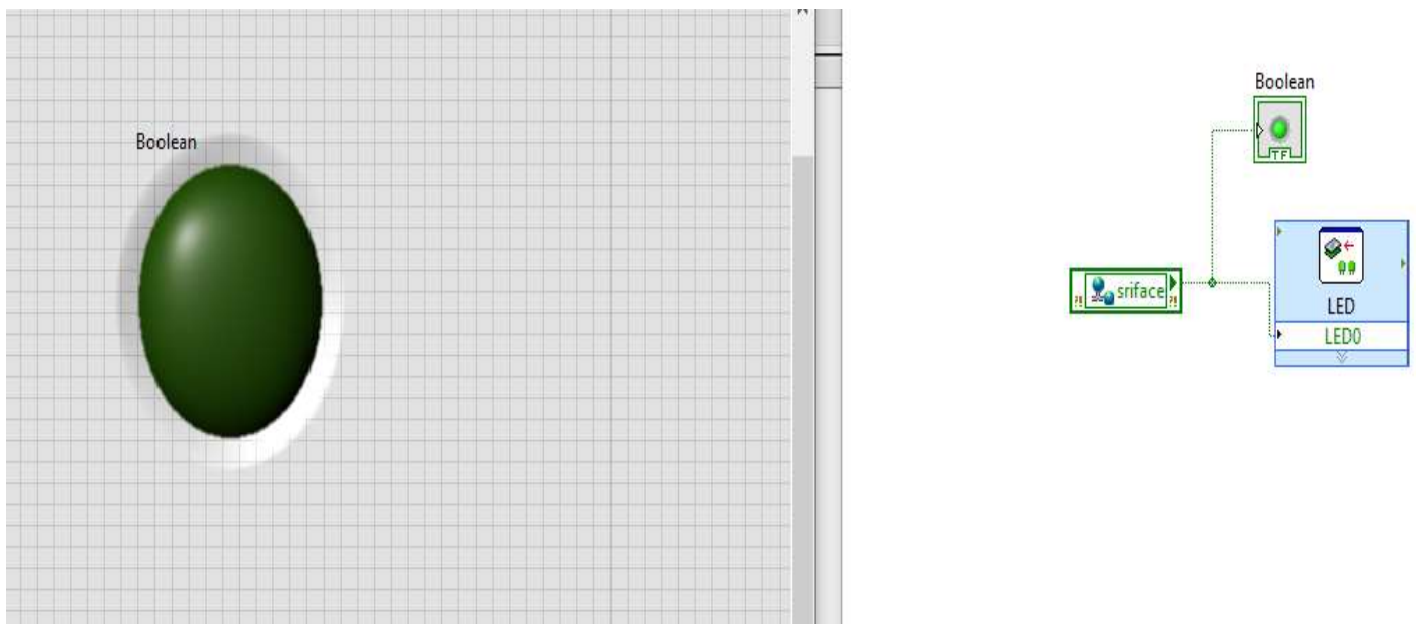

Fig 4: MyRio VI for interfacing hardware components

VI. RESULT

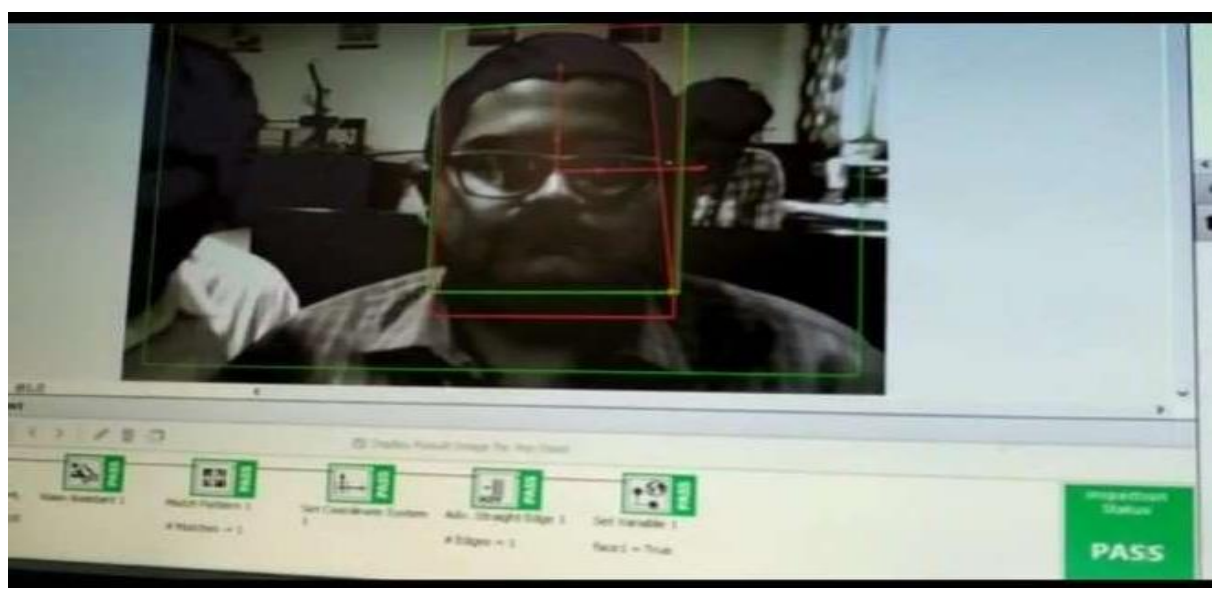

Vol. 3 (10), April 2020, www.ijirase.com 


\section{CONCLUSION}

Different techniques for facial recognition with the help of LabVIEW and vision builder AI softwares are used in this paper. Initially, Some ideas about generation of image are inspected for observing the effects of image acquisition process and in the image processing setup.

Thus the facial recognition area discloses the most effective method to utilize the image for Home security applications, by an instance of identification of object using various LabVIEW functions which also recommend the help of the great platform of LabVIEW for making hardware connections and furthermore image and vision preparation for various vision applications.

\section{ACKNOWLEDGMENT}

We the authors are thankful to NI Lab VIEW, academy lab, MLR Institute of Technology, Hyderabad, Telangana, India for providing the necessary facilities.

\section{REFERENCES}

[1] P. Zhao, H. Zhu, H. Li, and T. Shibata, -A DirectionalEdge-Based Real-Time Object Tracking System Employing Multiple CandidateLocation Generation,\| IEEE Transactions On Circuits And Systems For Video Technology, Vol. 23, No. 3, 503-517, Mar. 2013.

[2] J. Huang, A Fast Image Matching Technique for the Panoramicbased Localization, Okayama, Japan: 2016.

[3] Shuprajhaa,Subasree, Vaitheeshwari, Sivakumar, -A review on Image Processing techniques using Pattern matching in LabVIEW, IInternational Journal of Advanced Engineering Research and Applications (IJAERA) ISSN: 2454-2377 Vol. 1, Issue - 11, Mar. 2016

[4] M. S. Gururaj, M. H. Ramesh, J. A. Arvind, -A Review on Image Tracking Technique in Labview,\| ISSN: (24552631) IJSDR | Vol. 1, Issue 6. Jun. 2016 